\title{
VALLE-INCLÁN, LA FURA DELS BAUS: UNA MISMA MATEMÁTICA
}

Reconozco lo arriesgado del intento: enfrentar dos mundos aparentemente tan distantes y diversos. Valle o el teatro literario por excelencia; la novela teatral, la pasión del lenguaje hablado y de la palabra inventada. Y La Fura: el Espacio-Acción puro y duro; el espectáculo situado más allá (o más acá) de la palabra, en el gesto, en el ruido y en la contorsión provocativa, calculada, coral y coreográfica.

Sin embargo, tras un detenido análisis, surgen aspectos insospechados (el cálculo poético es acaso el más relevante) que conectan ambos tiempos, ambos modos de concebir el hecho teatral, identificándolos en una misma perspectiva: la Estética que estableciéndose más allá del llanto y de la risa, nos interroga, sin esperar respuesta alguna (tal vez despreciándonos), desde la misma decepción de la condición humana, desde el mismo gesto ambiguo de amor y odio por los que sufren, víctimas de los mecanismos fatales de la Historia. Un ámbito dramático, en suma, donde las emociones se neutralizan hasta provocar un estado de conciencia lúcido e "impasible", pero que de ningún modo significa un desentendimiento cínico de la realidad.

La pregunta inicial, pues, habría que plantearla de esta forma: ¿es posible establecer un análisis suficientemente explicativo de espectáculos y montajes como Accions (1983), Suz o Suz (1985) o Tier Mon (1987), desde la Poética del Esperpento? Y, si puede establecerse, ¿qué lazos vincularían ambas propuestas estéticas? ¿Podría igualmente postularse un semejante sustrato ideológico para ellas?

Avancemos algunas respuestas, esbozos de otras más amplias y pormenorizadas, que nos ayuden a comprender mejor dos de las más apasionantes manifestaciones del teatro español del siglo veinte.

Tomemos como puntos de partida algunas de sus unidades claves: Luces de bohemia (1920), Farsa y licencia de la Reina Castiza (1922) y Los cuernos de don Friolera (1925), por una parte, y Accions (1983), Suz o Suz (1985) y Tier Mon (1987) por otra. Analicemos, a continuación, el diseño de los personajes; la interacción radical entre Ética y Estética en el proceso de conformación de los mismos, y finalmente, la posibilidad de un semejante sustrato ideológico (lo que podría denominarse, una perspectiva de ultratumba). Y veamos qué sucede.

El diseño de los personajes: los dos estadios del Esperpento.

En el arte, como en la vida, destruir es crear...

Valle-Inclán (Corte de amor) 
En el camino del Expresionismo, acaso desde la conciencia del error, antes que del horror; y de lo terriblemente humano (terrible por lo insustancial de la tragedia), Valle informa a la tradicional capacidad universalizadora del Fantoche (desde su radical "españolaidad") con un dato nuevo: la desmoralización programática del mismo, un premeditado, medido e integral vacio ético que se nos señala como condicion sustancial de los seres de cartón y hueso que todos somos.

Pedro Salinas (1948) nos indica que Luces de bohemia descubre lo esperpéntico, pero sólo en su inicio ${ }^{1}$. Y así es; Max Estrella y don Latino son personajes dotados aún de una cierta controversia, que se manifiesta en conflicto interior: el drama de conciencia del primero, o la mala conciencia del segundo. La desmoralización o el vaciado deformante de estos personajes se da en la Acción, en un proceso dotado de contexto que constituye el espacio dramático de la obra. El joven anarquista, la madre con el hijo muerto en brazos, la esposa y la hija de Max se nos ofrecen como figuras "plenas" y emergentes, severos contrapuntos de referencia ética, en su inmovilidad de arquetipos. Pero la Farsa es incompatible con cualquier indicio, siquiera sospecha, de vida interior en los personajes, pues el Fantoche obtiene su carácter efectivo precisamente del entramado de gestos y de aspavientos que constituyen su "única" realidad dramática ${ }^{2}$.

Luces de bohemia es esencialmente una tragedia, en la medida que lo es también Don Quijote; el acceso definitivo a la Realidad Esperpéntica concluye con Los cuernos de don Friolera (1925). En este "verdadero" esperpento, Valle proclama que el teatro de nuestros días sólo es posible desde la impasible ataraxia de ultratumba; esto es, cuando la sentimentalidad ha sido debidamente sepultada y la controversia ha abandonado nuestros espíritus escindidos, para dar paso a una conciencia demiúrgica de la realidad.

He aquí cómo conviven en el Esperpénto dos posibilidades, ambas con idéntico poder aleccionador: el héroe deformado (Max Estrella) se ha convertido finalmente en muñeco histórico (La Reina Castiza, la gran comadre).

En el Esperpento Inicial, los héroes son "sujetos" susceptibles de degradación; sea debida a causas internas o a causas externas a sí, su desmoralización es un fenómeno

1 Pedro Salinas, “Significación del esperpento, o Valle-Inclán, hijo pródigo del 98”, en Literatura española. Siglo XX. Madrid, 1970 (reedición), pp. 86-114. La cita en p. 110.

2 En relación con lo expuesto, además del artículo citado en la nota anterior, se recomienda la lectura de dos interesantísimos trabajos: Anthony Zahareas, "The grotesque and the esperpento" en A: N. Zahareas et al. Ramón del Valle-Inclán: An Appraisal in his Life and his Works, New York, 1968, pp. 81-94. Y Gonzalo Sobejano, “Luces de bohemia, elegía y sátira” en Forma literaria y sensibilidad social, Madrid, 1969, pp. 232-240. 
gradual y se produce en el decurso de la acción: los héroes son víctimas de las que es posible "condolerse". En la formulación definitiva de la Poética del Esperpento, la degradación es previa a la Acción, bien desde el umbral mismo de la obra ${ }^{3}$, bien desde cualquier acotación desgranada como un aliento deshumanizador y animalesco ${ }^{4}$. Los personajes acuden al retablo del bululú ya cosificados e inmovilizados en su condición de fantoches, de tal manera que la piedad o la conmiseración no son posibles. Tampoco la risa.

Con un grupo de "jóvenes airados" que, a finales de los años setenta recorre con una mula y un carro las atestadas ciudades del cinturón industrial barcelonés, representando El Pages Tarino; que renuncia de antemano a cualquier ascendente, ya sea Artaud, Marinetti, Wiener Schul o el Aktionskunst, y que, en el inicio de los ochenta, se proclama, a propósito del Manifiesto Canalla, moderna "Tribu Urbana", no se puede intentar siquiera un apunte de crítica hidráulica (de fuentes). Sólo es posible hablar de respuestas semejantes, repetidas en el tiempo, a una misma angustia: el dolor de existir en un mundo de mercachifles "ordenado" ab initio, que nos escupe a sus márgenes, allí donde apenas llegan los ecos de las respuestas que pretenden explicarnos o, al menos, "justificarnos". Únicamente podemos intuir ese aliento de sarcasmo y de sardónica rebeldía que enlaza a Valle con Quevedo y, más allá, con el Arcipreste de Hita; o esa vena de estupor y de impotencia que el Teatro se abre en cada espectáculo de La Fura, sin lágrimas, sin risas, impasible como la realidad $^{5}$.

Se repite frecuentemente que el Esperpento es un hecho dramático de naturaleza esencialmente objetiva y narrativa altamente estilizado. Aparente paradoja esta que conjuga la objetivación y la estilización extremas del suceso teatral: es la Matemática Poética Aplicada. Si analizamos brevemente la íntima estructura de los más conocidos

3 Véase al respecto el DRAMATIS PERSONAE del esperpento La hija del capitán, o el APOSTILLÓN de Farsa y licencia... y compruébese el efecto cosificador de los mismos.

4 La vágula libélula de la sonrisa bulle sobre su boca belfa, pintada de carmín... esta es la representación del REY CONSORTE en la Jornada II de Farsa y licencia... un ejemplo espigado al azar, de los cientos que podrían aportarse, de esta tremenda capacidad "embrutecedora" del adjetivo valleinclanesco.

5 Toda la información y los datos expuestos en el presente trabajo referentes al grupo LA FURA DELS BAUS y a sus obras proceden de diferente material gráfico, de prensa diaria o editado por el propio grupo: fundamentalmente y en lo que concierne al espectáculo Tier Mon (1987), el Dosier titulado La Fura dels Baus, Tier Mon, realizado por Sixte Peláez (encargado de los textos y de la estructura verbal de Tier Mon); así como de las declaraciones de Jurgen Müller, director del espectáculo Tier Mon y miembro permanente del grupo, realizadas durante el mes de marzo de 1990 en Ljubljana, recopiladas por la periodista eslovena Urßa Gerłak. 
espectáculos de La Fura, comprobaremos que esa misma matemática se manifiesta en Tier Mon, Suz o Suz y Accions.

En lo que se refiere al diseño de los personajes, La Fura parte precisamente del Estadio Final del Esperpento; esto es, aquel en que los actantes; cosificados a priori, se convierten en hirientes y "espectaculares" fantoches arquetípicos (el Gran Preboste de Farsa y licencia o los Generales de La hija del capitán), significativos exclusivamente en el contexto de la obra, pero a cuyo través reconocemos el mundo real como parte de la misma.

En el Protagonista, en el Antagonista, en el Inútil y en el Enano; en el Personaje de Blanco (Protagonista) que "húmedo asciende". (Tier Mon, 1987), reconocemos, además, dos de las características que definen con mayor precisión la naturaleza del Fantoche valleinclanesco: su concepto visual y su carácter mítico.

Con respecto al concepto visual del Esperpento, resulta obvio el "sentido plástico" general que se desprende de la prosa y del entero proyecto artístico de Valle, tanto por la indudable influencia del cine en la obra de éste (no me resisto a la idea de relacionar visualmente algunos de sus muñecos con el Nosferatu de Murnau, 1922, o con el doctor Caligari de Robert Wiene, 1919), como por las raíces modernistas de la misma.

En el caso de La Fura, la influencia de la actual cultura visual en sus obras queda fuera de toda duda. No obstante, acaso por todo ello, el Home Fang o el Home Blanc de Accions (1983) o las figuras patibulares de las Forcas en Tier Mon, encuentran sus ancestros icónicos en las siluetas, mágicas y macabras, de Ligazon (1927), o en los fantasmones que reiteradamente, en la obra de Valle, se agitan en el inquietante claroscuro de la mecha de un candil o de la espectral luz lunar; en la medida que estos los encuentran (sus ancestros) en la "negra" paleta de Goya o en la desesperada pirueta de Quevedo.

Forcas - seis patíbulos - Muerte del coro. Desarrollo hacia la vida. 4.1.16 En las pértigas colocadas en los extremos de las Tarimas por mandato del personaje blanco cuelgan seis hombres a cinco metros de altura. Haces de luz cenital bañan sus cuerpos ahorcados... Tier Mon (textos de Sixte Peláez)

Cuando las estrellas hacen guiños sobre los tejados... Don Friolera, en el reflejo amarillo del quinqué, es un fantoche trágico. La beata se acerca, y pega a la reja su perfil de lechuza... Los cuernos de don Friolera. Escena IV.

La cortineja, suspensa de un clavo, deja ver la figura soturna y huraña, que tiene una abstracción gesticulante... Las Galas del Difunto . Escena II. 
En cuanto a esa atmósfera mitológica que envuelve por igual al Fantoche valleinclanesco y al Engendro furero, no deberíamos olvidar que, en el Grotesco, la distancia, si es "vindicadora" y violenta, como en el caso que nos ocupa, posee un fuerte contenido mítico, cuando no místico, que fácilmente puede rastrearse tanto en la obra de Valle como en la más reciente de La Fura.

El objetivo programático del primero se resolvía en la calculada formulación de un espacio dramático en el que Tragedia y Comedia se diesen confudidas en un solo rictus de rechazo estético (y ético) de la realidad "reconocida"; y en el que cualquier conmoción del espíritu quedase neutralizada por la íntima convivencia con su contrario. Era el programa, sustancialmente paradojico y mítico, de una parte del arte contemporáneo, aquella que finalmente renunciaba a sus orígenes románticos.

De modo general, el concepto matemático-poético de La Fura, a partir del cual, como en el Esperpento ${ }^{6}$, se descompone la realidad mundana para reconstruirse significativamente en realidad teatral, se da fundamentálmente en el Espacio y, una vez que se renuncia a la palabra, en la Acción gestual. La realación Espacio-Gesto-Tiempo, de la que surge la noción de ritmo dramático, alcanza una alta cota expresiva en Tier Mon (1987), espectáculo en que la colocación y la distribución sonora de los elementos gestuales consiguen una objetivación y una estilización máxima, con carácter bien "aleccionador"

Las distintas fases y nexos del espectáculo presentan diferentes lados de la idea de Poder y de su relación con el individuo y la Humanidad Tier Mon. Aspectos. Dosier.

bien significativo

Esta idea de Poder se plantea desde un origen establecido por el Destino hasta la más radical de sus consecuencias, la Muerte, pasando por diversos grados de iconicidad - el conflicto bélico, la diáspora, la muerte, la jerarquía social y la manipulación del individuo, que en el espectáculo reciben los nombres de Guerra, Éxodo, Forcas, Menjadora, Artilugio -. Tier Mon. Aspectos. Dosier.

Síntesis del “Aspecto Argumental” de Tier $\mathrm{Mon}^{7}$

6 Ricardo Doménech, "Para una visión actual del teatro de los esperpentos” en Cuadernos hispanoamericanos, núm. 199-200, Madrid, 1966. En la página 464 de este interesante trabajo, dice así: El esperpento descoyunta, si es que puede decirse así, la realidad: trastorna por completo la imagen aparente que tenemos de su estructura y de su dinámica, precisamente para mejor mostrarnos cómo son, cómo es la realidad. 
A pesar de que las distintas partes tienen carácter propio no implican una sucesión lógica ni dramática. Es cierta relación natural de personajes, partes y nexos que poco a poco configura el tejido del espectáculo y resuelve el plazo de Tier Mon. Es con la forma elíptica que va de la primera parte de "presentación" - desfile - a la última de "resolución" - rotatorio -, con lo que se estructura y define el aspecto argumental. Aspectos. Dosier.

\section{PARTES.}

1 - Presentación. Aparición Protagonista, Antagonista y Coro.

\section{DESFILE.}

\section{NEXO.}

2 - parte. Conflicto Antagonistas y Coro.

\section{GUERRA.}

\section{NEXO.}

3 - parte. Número coral. Búsqueda. ÉXODO.

4 - parte. Número coral. Muerte. FORCAS.

5 - parte. Poder del Protagonista sobre Coro.

\section{MENJADORA.}

Interior. Seis pequeños habitáculos... Esperan algo... A uno le da una manzana... Hay lamentos por ese trato de favor... (Y) vierte garbanzos sobre las cabezas de los escandalosos devoradores alborotadores. Libera a los castigadosy (a su manera borde) les proporciona alimento consistente. Se lo comen todo... y de postre barras de pan... Panchos satisfechos se salen de sus cajas. Más hostiles, más egoístas, no es lo que esperaba de ellos. Se desbordan. El personaje de blanco... aborta la posibilidad de más abusos. Los pollos se desnudan. Sudan el chute. El juego ha finalizado, el calor... los despacha con caras destempladas hasta el confin. Nexo. castigo del coro. Perdón del coro.

7 La síntesis se realiza a partir de los textos de Sixte Peláez, autor de la estructura verbal de Tier Mon: Ver nota 5 . Se hace especial hincapié en la parte titulada MENJADORA (comedero) pues resume en sí los aspectos fundamentales de la Poética del Esperpento: descompone la realidad, para después recomponerla en términos de calculada deformación, mediante una estilización grotesca de los elementos que la integran; con el fin de expresarla y representarla tal cual es, sin referencia alguna a motivaciones distintas de las expresadas con palmaria evidencia por la acción de los fantoches o actantes. 
6 - parte. Sumisión del individuo por los Antagonistas.

ARTILUGIO.

7 - Resolución. Muerte de los Antagonistas. Desaparición de la Humanidad y del Protagonista.

CODA. ROTATORI.

Etica, Estética y Violencia.

Jugar en los tiempos que corren es inmoral, es una canallada...

Valle-Inclán.

Desde el punto de vista del autor, el Fantoche posee hondas raíces éticas, siempre que la "decisión estética" obedezca a fundamentos esencialmente éticos. Por el contrario, si la conducta ética se entiende como patrón individual y autónomo de representación y acción frente a la realidad, sea ésta de naturaleza artística o no, el Fantoche tanto en el Esperpento Final como en los Montajes de la Fura, es un Ente Vacío.

Es en esta aparente contradicción donde se acrisola precisamente gran parte del arte y del teatro moderno; la "deshumanización" de sus engendros: el "vacío ético" de sus criaturas, obedece a un posicionamiento radicalmente moral y ético del artista demiurgo. Se ha hablado de Mística de la Violencia refiriéndose a Valle-Inclán y a su obra; no es otra la raíz mixtificadora que alienta la producción de la Fura Dels Baus. Tal vez, conscientes de la inutilidad esencial del intelectual, en el sentido "adorniano", la beligerancia se convierte en tarea inexcusable del marginado. Para los situados "al margen", existen razones para la decepción, pero no para la neutralidad, el arte, como la vida, debe ser "violentado".

Pío Baroja y Azorín quedaron anclados en el mundo de la preguerra: dominado por Nietzche y Shopenhauer. Valle, Unamuno y Antonio Machado entraron de forma problemática, individual y contradictoria en el siglo veinte, sacudidos por los dos fenómenos que lo abren: el acceso del proletariado, de las masas, al estatuto de clase "efectiva"; y el descubrimiento del "Inconsciente", hechos que exigían del intelectual una "recolocación" con respecto a la realidad: marcada tanto por el tránsito que va de la búsqueda individual al compromiso como por la asunción de nuevas fórmulas y nuevos materiales que diesen concreción al hecho artístico.

La Fura se encontraría en el final de la curva de este arco tensado que es el siglo en curso: el proletariado, fragmentado, ha sido reducido de nuevo a masa informe que consume y produce en un entramado de relaciones que ya no domina. El Inconsciente ha saltado en pedazos en medio de un cerco "informativo" que satura y rebosa el ámbito de la conciencia, hasta ahogarlo colectivamente o "conducirlo" individualmente mediante la publicidad y la propaganda.

Valle es un autor fascinado por la palabra, La Fura es un Creador Colectivo que renuncia a la verbalización de los conflictos; sin embargo, el sentido de marginalidad y de extrañamiento con respecto al orden dominante y al arte oficial, es el mismo en 
un extremo y otro del mástil. Han pasado setenta años, pero la voluntad de rechazo "violento" es idéntica y uno solo, el sarcasmo.

Matemática y Muerte del Teatro.

Don Estrafalario : Yo quisiera ver este mundo con la perspectiva de la otra ribera...

Se ha escrito que la Matemática del Esperpento, como visión de ultratumba, se agota en sí misma, que presupone la muerte del teatro ${ }^{8}$. Sin embargo, una vez inventado el cine, abrumados por la televisión y pendientes del magnetoscopio casero, ¿qué otra posibilidad resta al teatro de nuestra época? Cuando todos deseamos ser el Dios Blanco y nos identificamos culpablemente con él, es inútil esperar aplausos o conmoción espiritual alguna. Por eso, cuando un espectáculo de La Fura concluye, los actores nada esperan y nada reciben. Tampoco durante el transcurso del mismo, pues se nos ignora deliberadamente.

El público es un elemento espacial funcionalmente "ausente". De esta presencia-ausencia paradojica y engañosa deviene gran parte de la tensión y de la violencia que nos embarga cuando "creemos participar" en un espectáculo de La Fura. Es la consecuencia del desprecio, de vernos reflejados en el espejo cóncavo del arte, sin concesiones, sin piedad, sin motivaciones ocultas que nos engradezcan $o$, al menos, nos justifiquen.

Trescientos jovenes, ocupantes ilegales de viviendas, después de una víspera marcada por disturbios y enfrentamientos con la policía, vestidos de cuero negro, esperan, más allá de la risa o đel llanto, en Berlín, o en cualquier đepósito de cadáveres de cualquier gran urbe, o en un matadero municipal, o en una vieja fábrica abandonada, o en un antiguo cuartel, eso es el Esperpento. Entre los jóvenes, hay maduros profesionales de la clase media también, profesores universitarios y curiosos, todos forman parte del espectáculo, son la rugosidad cóncava del mismo, la materia rídicula, cruel y patética del títere.

La Fura ha reencontrado así el camino del Fantoche Unidimensional, que señalo una de las muertes del teatro, y cuyos mausoleos son la Comédie Française, la Royal Academy o el Centro Dramático Nacional. El teatro ha muerto, viva el espectáculo.

8. José Fernández Montesinos, “Modernismo, esperpentismo, o las dos evasiones” en Revista de Occidente, núm. 44-45, 1966, pp. 152-160. 